\title{
New sexism in couple therapy: A discursive analysis
}

Olga Sutherland

University of Guelph

Andrea LaMarre

University of Guelph

Carla Rice

University of Guelph

Laura Hardt

University of Guelph

Amanda Le Couteur

The University of Adelaide

This is the peer reviewed version of the following article: Sutherland, O., LaMarre, A., Rice, C., Hardt, L., \& Le Couteur, A. (2017). New sexism in couple therapy: A discourse analysis. Family Process, 56(3), 686-700., which has been published in final form at https://doi.org/10.1111/famp.12292. This article may be used for non-commercial purposes in accordance with Wiley Terms and Conditions for Use of Self-Archived Versions.

\section{Recommended citation:}

Sutherland, O., LaMarre, A., Rice, C., Hardt, L., \& Le Couteur, A. (2017). New sexism in couple therapy: A discourse analysis. Family Process, 56(3), 686-700. https://doi.org/10.1111/famp.12292 


\section{New Sexism in Couple Therapy: A Discursive Analysis}

Olga Sutherland, Andrea LaMarre, Carla Rice, Laura Hardt, and Amanda Le Couteur

\section{Abstract}

The persistence of gender inequality in postindustrial societies is puzzling in light of a plethora of changes that destabilize it, including shifts in economy, legislation, and the proliferation of feminist politics. In family relations, such persistence manifests as a disconnect between couples aspiring to be more egalitarian yet continuing to enact traditional gender roles and hierarchies. There is an emerging consensus that gender inequality persists because of people's continued reliance on sexist ideology or gendered assumptions that constitute women as innately distinct from and inferior to men. Sexist ideology changes its form to accommodate to changing socio-economic conditions. Contemporary forms of sexism are old ways of legitimizing male power articulated in new and creative ways, often by incorporating feminist arguments. To effectively recognize and address "new sexism," scholars and practitioners require new, innovative research frameworks. Our objective in writing this article is two-fold. First, we seek to advance discursive (i.e., focused on language in use) approaches to the study of sexism. Second, we present the results of a discursive analysis of "new" sexist discourse in the context of couple therapy. The study provides preliminary evidence that, despite endorsing egalitarian norms, couples studied continue to rely on gender binaries and remain entrenched in old-fashioned patterns of gender inequality. 
Implications of these results for the practice of couple therapy and for future research are discussed.

Keywords

Sexism; Gender; Membership Categorization Analysis; Discursive Psychology; Conversation Analysis; Couple Therapy; Couple Relationships

Despite changes in gender ideology in liberal democratic societies, gender inequalities within intimate relationships persist (Boeri, Del Boca, \& Pissarides, 2005; Kan \& Gershuny, 2010). The ideological image of male breadwinner and female homemaker has largely lost its appeal and no longer captures the lived experience of many couples and families ${ }^{1}$ (Davis \& Greenstein, 2009; Monahan Lang \& Risman, 2006). One would expect that contemporary discourses of equality and women's emancipation would translate into more diversified performances of gender and intimate relationships. Yet, empirical evidence suggests otherwise, namely, that couples continue to enact traditional gender roles and hierarchical relations (Gerson, 2010; Knudson-Martin \& Mahoney, 2009). There is a growing consensus that inequalities between men and women across societies persist because of continuing sexism (Brandt, 2011; Glick et al., 2000; Ridgeway, 2011; Risman, 2012). Sexism is prejudice, stereotyping, or discriminating against people on the basis of their gender (Bates, 2016).

\footnotetext{
${ }^{1}$ We retain the conventional terms "couple" and "family" while acknowledging that their use may be inconsistent with our social justice agenda, as they may evoke and reinforce culturally dominant (heteronormative, mononormative, patriarchal, western, white) constructions of kinship based on marriage, monogamy, and "bloodline" and leave invisible alternative forms of intimacies and life-sustaining relationships (Butler, 2004).
} 
Women continue to be the main target of sexism (Brinkman \& Rickard, 2009). Whereas gender prejudice involves negative attitudes toward women (e.g., women are inferior to, or less worthy than, men), gender stereotypes are fixed or oversimplified ideas concerning characteristics or predispositions of members of gender groups (e.g., men tend to be less emotive than women).

More recently, sexism has become more covert and subtle (Becker \& Swim, 2012). Hostile or negative attitudes toward women are less likely to be openly expressed and have been replaced by more benevolent forms of sexism involving positive yet patronizing ideas (e.g., women require men's protection; as mothers of children, women need to be cherished; Glick \& Fiske, 2011). Benevolent sexism encourages women's alignment with stereotypical gender role behaviors. It presents women as fragile (Overall, Sibley, \& Tan, 2011) and reduces their career aspirations, work-related performance, and willingness to adopt independent roles outside the home (Barreto, Ellemers, Piebinga, \& Moya, 2010; Rudman \& Heppen, 2003). Benevolent sexism persists, and elicits less social pressure for change than hostile sexism, in part because benevolent beliefs are positively valanced (Glick \& Fiske, 2011) and less likely to be recognized as sexist (Blodorn, O'Brian, \& Kordys, 2012).

In contemporary postsexist culture that claims sexism is no longer relevant or alive, women face the challenge of naming and resisting persistent sexism (Gill, 2011). Contemporary manifestations of sexismvariably referred to as new sexism (Gill, 2011), neosexism (Tougas, Brown, Beaton, \& Joly, 1995), modern sexism (Swim, Aikin, Hall, \& Hunter, 1995), or ambivalent sexism (Glick \& Fiske, 2011)-take this challenge to a new 
level. As "old" sexist arguments are repackaged in ways that are more palatable and invisible to an egalitarian audience, they become more difficult to counter. One feature that makes new sexism particularly effective is its denial of sexism: Through creatively embedding feminist arguments within pronouncements that advance patriarchal interests, it capitalizes on common-sense notions that gender inequality is a thing of the past, and that women are now liberated (Gill, 2011). The development of new, subtler, and "softer" forms of sexism is likely owed in part to cultural intolerance of overt sexism (Condor, Figgou, Abell, Gibson, \& Stevenson, 2006; Riley, 2001). As new forms of social and economic organization emerge, gender as a frame for categorizing and ordering people does not disappear; rather, it is infused into these new forms (Ridgeway, 2011). Stereotypes that support inequality are retained, but nuanced, transformed, or qualified, making new sexism less detectable and challengeable.

Sexism is a persistent issue that needs to be addressed in order to accelerate progress toward gender equality. Sexist attitudes justify and perpetuate gender discrimination and oppression, with significant costs for women's well-being and couple relationships. Negative impacts of sexism include intimate partner violence, restriction of women's rights and freedoms (e.g., work, earnings, education, delay of first pregnancy or child), unfair division of domestic labor, and reduced quality of relationships (for a review, see Davis \& Greenstein, 2009). A recent meta-analysis demonstrated a negative association between sexism and psychological well-being across 23 correlational studies (Schmitt, Branscombe, Postmes, \& Garcia, 2014). In order to develop successful initiatives to combat persistent sexism, detailed knowledge is needed concerning contemporary 
forms of sexism. Much of the prior work has examined how sexism operates to maintain gender inequalities at a societal level or in the relationship between men and women as groups rather than as partners in intimate relationships (Brandt, 2011; Glick et al., 2000). Little research has explored the processes of sexism in intimate relationships, which are pivotal for understanding how sexist attitudes are routinely produced and challenged in the daily interactions between partners. Gender scholars have long suggested that heterosexual relationships comprise the primary site of women's subordination (Ingraham, 2006; Sharp \& Keyton, 2016), which makes the analysis of interactions between partners in heterosexual relationship configurations particularly important.

\section{Objectives and Theoretical Framework}

The aim of the study is to investigate how sexism is (re)produced, both overtly and indirectly, through couples' interactions in the context of couple therapy. The study was guided by the following research questions:

(a) how participants in contemporary couple therapy (partners and therapists) use language to issue and respond to sexist claims, and (b) how they attend to and deal with potential attributions of sexism or their talk being heard as sexist. Although our focus was on clients' talk, we also examined therapists' contributions to discourse.

A variety of theoretical lenses have been used to examine sexism (Lorber, 2012; Mannino \& Deutsch, 2007). Social constructionist explanations have gained popularity in recent years (Deutsch, 2007; Knudson-Martin, 2015; Lorber, 2012; Ridgeway, 2011; Risman, 2012) and this framework informed this study. Constructionists see gender as a social structure that infuses life at individual, interactional, and institutional levels 
(Ridgeway, 2011; Risman, 2012), arguing that people re-produce a gendered social order through social interaction (Deutsch, 2007; Lorber, 2012). Gender, from this perspective, is not an enactment of an individual but a system of meaning that is reproduced socially and interactionally. The study was also informed by intersectional insights (Cole, 2009; Crenshaw, 1991), particularly the anticategorical intersectional perspective that presumes that intersecting categories are fluid and socially constructed (McCall, 2005). We moved beyond focusing on gender as a discrete socially constructed category to considering how gender intersects with other "axes" of difference (e.g., sexuality, class, age, geography, and ability). For example, we examined how partners constitute each other as incumbents of multiple social categories (single woman, disabled man, etc.) with distinct rights and responsibilities and what social functions such constructions serve in the contexts of their production.

More specifically, we drew on discursive psychological, conversation analytic, and other discourse analytic approaches to the study of sexism and other -isms (Augoustinos, 2016; Augoustinos \& Every, 2010; Billig et al., 1988; Robles, 2015; Speer, 2015; Stapleton, 2015; Stokoe, 2015; Whitehead \& Stokoe, 2015). Discourse analytic inquiry offers an antidote to more conventional cognitive models of sexism (Glick \& Fiske, 2011) that locate sexism in the individual mind or frame it as a person's inaccurate or oversimplified perceptions of, and attitudes toward, members of certain social groups. Informed by discursive perspectives, we investigated sexism as sexist discourse. Sexist discourse can be defined as "'language in use,' either spoken words or written texts, which stereotypes or discriminates against a person or group of people based on their gender" (McPhillips \& 
Speer, 2015, p. 1; Whitehead \& Stokoe, 2015). From a discursive perspective, discourse constitutes the primary site for grasping how sexist ideas are socially re-produced (Speer, 2002). Prejudiced utterances are not inherently negative but gain their problematic status through social interaction and negotiation of meaning (Speer \& Potter, 2000). That is, the meaning of an utterance (e.g., sexist or not) does not "reside" in this utterance or manifest uniformly across contexts; rather, it is fluid, contextdependent, and jointly produced by people in interaction (McPhillips \& Speer, 2015). Discursive scholars avoid "the use of decontextualized statements and a priori definitions" of sexism and instead focus on how participants orient (or not) to their own and others' talk as sexist, racist, or heterosexist (Speer \& Potter, 2000, p. 547; Whitehead \& Stokoe, 2015). Discursive scholars have identified a range of practices speakers may use to deflect negative attributions and protect their identity, including disclaimers (I am not sexist but...) or denials and mitigations of prejudiced claims (I am not saying women don't have a right to choose, but...). They refer to these rhetorical strategies as "new" forms of sexism and other isms (Augoustinos \& Every, 2010). This work reveals that people increasingly treat overt prejudice as an accountable matter or something to be suppressed in social relationships (Condor et al., 2006; Stapleton, 2015) and highlights the importance of examining more covert forms of sexist interaction.

Prior discourse analytic work on gender and other kinds of prejudice has explored informal social interactions (Robles, 2015; Speer \& Potter, 2000; Stapleton, 2015). Scant empirical attention has been given to how sexist claims are issued and managed in professional encounters, such as 
interactions in the context of radio talk, medical and therapeutic encounters, or mediation (for some exceptions see Stokoe, 2015; Whitehead, 2015). Such analyses can help identify distinct, setting-specific discursive practices and clarify how professionals may be implicated in the reproduction of sexist discourse as well as offer insight into how they may foster social change on the ground. Discursive analyses can help shed light on the situated production of sexist discourse and recipients' responses to sexism in the moment-by-moment context of their production.

\section{Approach}

To examine sexist discourse, we used a blend of membership categorization analysis (MCA; Hester \& Eglin, 1997; Housley \& Fitzgerald, 2015; Sacks, 1992; Stokoe, 2012), discursive psychology (DP; Edwards \& Potter, 1992; Tileagă \& Stokoe, 2016), and conversation analysis (CA; Sacks, 1992; Sidnell \& Stivers, 2013). MCA is focused on people's use of membership categories in accomplishing routine social activities (Hester \& Eglin, 1997; Housley \& Fitzgerald, 2015). Analysis is concerned with "observing, uncovering and detailing the methods, techniques, and orientations employed by members as they go about their routine tasks" (Housley \& Fitzgerald, 2015, p. 6). Categories may include "wife," "son," "man," "5-year-old," and so forth. Membership categories that are used together can be heard to belong to the same membership categorization device or collection, for example, "daughter" and "father" can be heard to belong to the device "family" (Sacks, 1974). MCA is also concerned with category-bound predicates-the activities, obligations, rights, or characteristics conventionally associated with certain categories (Jayyusi, 1984; Sacks, 1974). In contrast with work that studies identity from an 
external (observer) viewpoint, MCA attends to how participants in an interaction treat social "identity" or group membership and how they achieve and negotiate it in practice. MCA moves beyond noticing that participants use certain categories, aiming instead for detailed analysis of how categories are used for various social purposes such as blaming, refusing, justifying, or complimenting (Housley \& Fitzgerald, 2015; Watson, 2015). In studies of gender, MCA helps explore how gender differences are constituted with the aim of enhancing gender flexibility and promoting nongendered practices in social relations (Gergen, 2010).

Similar to MCA scholars, discursive psychologists (Edwards \& Potter, 1992; Tileagă \& Stokoe, 2016) treat people's use of language as constructive or as producing certain versions of events or persons. A DP approach to the study of categories helps clarify how people's membership in specific categories is rhetorically assembled (Edwards, 1998; Tileagă \& Stokoe, 2016). DP's emphasis on how reports are built as factual and how speakers position themselves as objective or disinterested is particularly relevant to our aims. In the current study, we assumed that, during therapy, couples are likely to offer competing notions of morality ("good" or "proper" spousal conduct) and descriptions of persons and events. We sought to offer a detailed interpretive account of the negotiation of such meanings in therapy. DP is closely aligned, more so in recent years (Edwards \& Stokoe, 2004), with the analytic concerns and procedures of CA-that is, describing the fine detail of the routine practices people use to accomplish social action and interaction, such as how people take turns at talk, organize their interaction sequentially, or repair misunderstanding (Sacks, 1992; Sidnell \& Stivers, 2013). Conversation analysts record naturally occurring 
interactions and transcribe them in detail, including such features as pauses, intonation, and pitch. We studied sexist claims as sequentially situated (i.e., produced in response to, and in anticipation of, the actions of others in interaction), rendering relevant and useful a CA focus on the sequential organization of interaction.

\section{Data and Procedures}

Our goal in this paper is to illustrate how discursive approaches can be used to study sexism, with subsequent studies more comprehensively examining sexist discourse. The data used here come from a larger study on social identity and discourse in family therapy. We inherited an archive of audio-recorded therapy sessions that took place between 2009 and 2013 at a family therapy center located at a Canadian university in a small-sized city. As a part of their program, students work with a mixed urban and rural catchment of ethnically and socio-economically diverse community clients under clinical faculty supervision. From this larger corpus of data, sessions involving heterosexually presenting couples that featured explicit reference to membership categories (e.g., men, fathers, guys, mom, son, bisexual) were selected. The first author (family therapy faculty) listened to the selected sessions and narrowed down the list to three sessions that involved blame-account sequences of action. From each session, she selected a prolonged stretch of interaction for a more detailed analysis (13, 19 , and 10 minutes in length) and transcribed them using standard orthography. Shorter excerpts were then selected to illustrate categorization practices. We did not use a more detailed CA transcription, given our focus on categorical aspects of talk rather than its sequential organization, although we recognize the limitations of not having access to 
prosodic and other features of talk in making categorization-related claims. The first author identified and documented a range of categorization and other practices in the data. The other members of the research team subsequently reviewed and edited this interpretive account. We used general MCA guiding principles and concepts (Housley \& Fitzgerald, 2015; Stokoe, 2012, pp. 281-282) in a four-step process: (a) data collection and exploration of the use of categories within a specific site, namely blameaccount sequences of actions in couple therapy; (b) building a collection of explicit mentions of categories; (c) locating a category within a sequential unfolding of interaction and exploring its form and function (e.g., to attribute blame, to justify one's conduct); and (d) identifying participants' orientations to the relevance of a specific category and how the category's use contributes to the trajectory of talk.

In line with other MCA scholars (Stokoe \& Attenborough, 2015), we adopted a case study approach to show how categorizations are produced in situ. Our aim was not to systematically examine categorization practices in couple therapy, but to identify the possible uses of categories. Examining a large corpus of data, though valuable from a perspective of identifying regularities and site-specific practices, does not allow for the focus on nuance and complexity that we aimed to achieve from prolonged engagement with a small sample of data in a case study. We did not have access to demographic data about the couples. Although qualitative researchers tend to follow the conventional quantitative practice of offering sample descriptions, they rarely explain why such information is relevant or how they use it (Morse, 2008). These characteristics were not relevant to our study, as our preference was to theorize and examine categories as 
participants' situated concerns and interpretive resources, rather than as our own analytic resources (Edwards, 1998). Although we recognize our interpretive presence in the process of analysis (e.g., our common-sense cultural knowledge concerning gender), our analytic focus was on participants' orientations to categories in their talk (Stokoe \& Smithson, 2001).

Prior discursive studies of family therapy (Buttny, 1990; Edwards, 1998; O'Reilly, 2014) have only peripherally investigated membership categories (for an exception, see O'Neill \& LeCouteur, 2014). More work is needed to explore clients' and therapists' use of categories to construct and negotiate spousal roles and relationships in couple therapy. Such analyses can help clarify how binary notions of gender roles are produced by presenting certain activities as naturally bound to gender categories.

\section{Results}

\section{Emma and Jack}

Emma (E) and Jack (J) came to therapy to address marital distress following the birth of their first child when $\mathrm{J}$ had an affair, which led to the partners separating. They wanted to make sense of the affair and explore the possibility of reconciliation. In Excerpt 1, E confronts $\mathrm{J}$ about his absence as a caregiver after their child was born and $\mathrm{J}$ accounts for his actions. Here and in other excerpts, we illustrate three categorization practices: description as categorization, categorical transformation, and categorical ambiguity.

Excerpt 1: Emma and Jack (25 minutes into the second session) 
1 E: So I think that because he was still like tanning, working out, going to baseball,

2 don't want to cry (starts crying) doing all these things, which is fine because this is

3 his prerogative, that's what he wanted to do, but I felt a little bit like I was alone as

4 a new mom

5 T: Uh huh

6 E: I would ask him to spend half an hour a day with Alex (daughter) and it was hard

7 for him to do, you know I felt like

$8 \mathrm{~J}: \quad$ But it's different when they are newborn too cause there is not a lot you can do as a

9 father, there is not a lot you can do. If I am doing the cooking, I am doing the

10 cleaning of the house, I am doing everything so that all she has to do is feed the

11 baby every two hours

12 E: But I guess it's just different priorities. Your priority was to clean the house, my

13 priority was for you to spend time with Alex (continues crying). I would rather

$14 \mathrm{~J}$ : But what time can you spend with your daughter when she is two, a month old?

15 E: Well I was doing it, all day every day, but and it wasn't just feeding, it was like

16 reading her stories or singing her songs

$17 \mathrm{~J}$ : I think because it was so overwhelming for you at the start and that's why you felt

18 this way. Like really. I talked to other friends and all the guys that l've talked to say

19 the same thing 'what can you do, that is nothing that you can really do as a guy for

20 the first couple of months, they are so.' I guess I could have held, I held as much I

21 could. I did really Emma, there is not a lot you can do

This example shows the use of a disjunctive category set (Jayyusi, 1984) involving alternative characterizations of $\mathrm{J}$ as a "bad spouse" versus "good spouse." $\mathrm{J}$ is alternatively described as someone who does not follow-up on his moral commitments and as someone who meets and even exceeds them. Although the category "wife" and its complement "husband" are not explicitly referenced in this interaction, they are evoked through E's description of herself as unsupported and abandoned by $\mathrm{J}$ (I was alone as a new mom). Here, the category "mother" implicates that of "wife," and wife evokes a set of rights in relation to the husband (e.g., to be supported and cared for). $\mathrm{E}$ categorizes $\mathrm{J}$ as a type of spouse who violates spousal obligations (lines 1-4). She does not explicitly assign $\mathrm{J}$ to the category "bad spouse" but delivers categorization through a description of his actions (tanning, working out, going to baseball) in terms of their consequencesher emotional distress displayed in the session (crying) and expressed 
linguistically (I felt like ... I was alone as a new mom). J's conduct is portrayed as an example of a social action that evokes tears and sadness in a spouse and damages intimate relations. The use of a description of actions and emotions to deliver categorization may be a way for $E$ to attribute blame to $\mathrm{J}$ without being heard as a partner whose own predispositions, specifically the propensity to judge and criticize her husband, might explain their relational problems. Embedded in her blaming is a normative (more egalitarian) conception of a spousal role, characterized by greater spousal involvement in caregiving.

$\mathrm{J}$ observably hears E's description of him as blame, evident in his efforts to account for his actions (lines 8-11, 14, 17-21). He works to deny that he did not support $E$ in her caregiving responsibilities by broadening the scope of what counts as caregiving or, in MCA terms, expanding a list of predicates or activities normatively associated with the category "caregiver." Specifically, J constructs himself as routinely and extensively, if not single-handedly, completing various domestic and caregiving tasks ( $I$ am doing the cooking, I am doing the cleaning of the house, I am doing everything...), using a three-part list construction (Jefferson, 1991), which undermines the claim that he is domestically uninvolved or a bad partner (lines 9-10). Implied here is J's commitment to egalitarianism evident in his willingness to undertake nontraditional household tasks. While claiming membership in the category "caregiver," $J$ sets limits on his ability to provide care as a "guy"- he can do anything other than care for a newborn. Constructing childcare as reducible to feeding (so that all she has to do is feed the baby every two hours, there is not a lot you can do as a father) presents this task as E's primary or sole obligation and implicitly evokes 
men's biological incapacity to breastfeed. Embedded in this construction is the traditional (sexist) notion that childcare is an inherently female activity.

$\mathrm{J}$ uses the categorization practice of categorical transformation to issue a stereotypical claim that childcare is women's business. The stereotype is transformed or modified here and, as a result, is difficult to recognize. Categorical transformations identified in prior MCA research include a category being transformed into another category ("boy" into "man") or a category being transformed into a collection or collection into a category (Hester \& Hester, 2012). Here, J mobilizes the gendered category "father" (rather than a gender-neutral category "parent") and evokes stereotypical gendered notions of men being providers and women being caregivers. Rather than employing an already culturally available category "father" and a category-bound predicate "noninvolvement in childcare," J capitalizes on this cultural stereotype, yet modifies it. He retains the category predicate "noninvolvement" but attaches it to a new category"father of newborn." The category "father" is a part of a broader collection of categories, "family," that contain other subcategories (e.g., son, granddaughter, niece, mother). $\mathrm{J}$ transforms a category into a collection (Hester \& Hester, 2012) using a stage-of-life (age) categorization device (Sacks, 1974). "Father" becomes a collection of categories (fathers of newborns, fathers of teenagers, etc.). This categorical transformation helps produce a contrast between, on the one hand, fathers of newborns and, on the other hand, other fathers and mothers. Whereas these other parents may be expected to engage in childcare, fathers of newborns are distinctly excused from it. The modal construction can in there is not a lot you can do claims fathers' (men's) limited capacity to contribute to the care of a 
newborn. J presents his view as a perspective held by men generally (all the guys that I've talked to say the same thing..., lines 18-20) rather than being motivated by personal interest, such as being excused from work. These discursive practices help to transform his fatherly noninvolvement from problematic to understandable: As a male caregiver/homemaker, he does everything he can, and should not be blamed for not performing tasks which he "by nature" is unable to perform.

We argue that such categorization practices are not incidental to the business of self-presentation. If $\mathrm{J}$ were to simply insert the category "father" and its predicate, the absence from childcare, he could be accused of being sexist. As a result, his justification for this absence would be open to challenge. Delimiting the category "father" in terms of child age provides a legitimate, temporary warrant for excusing fathers from childcare and aligns more closely with egalitarian standards for spousal roles. Accordingly, caregiving remains subtly framed as a gendered activity that is naturally bound to the category "women."

While $\mathrm{J}$ ties childcare to gender, $\mathrm{E}$ undermines gender differentiation by producing a gender-neutral conception of parental roles and obligations (lines 15-16). She self-categorizes as a "parent of a newborn" without explicitly referencing this category but through describing herself as routinely engaging in category-bound activities. Not referencing a category conceals gender; it is ambiguous whether she means that caregiving of a newborn is labor-intensive for a parent in general or for a mother. It is possible that if $E$ used the gendered term "mother," $J$ could continue using gender as a basis of his warrant to not be involved. To downplay the relevance of gender to caring for a newborn, she adds gender-neutral 
caregiving activities (reading, singing) to activities conventionally seen as done by women (breastfeeding).

In Excerpt 1, both partners implicitly endorse the egalitarian ethos, specifically the idea that the partners should share childcare responsibilities. What they seem to contest is the meaning of what $\mathrm{J}$ is able to do as a father of a newborn. In Excerpt 2, the partners similarly claim a commitment to egalitarianism. However, while acknowledging a violation of egalitarian norms, the male partner supplies explanations designed to excuse his conduct.

\section{Claire and Bill}

Claire (C) and Bill (B) are a married couple who sought a therapist to address "trust issues" attributed by both partners to B's past emotional affair and his difficulty to consider C's preferences. Here, and in other parts of the session, $\mathrm{C}$ blames $\mathrm{B}$ for failing to respect her possessions and not involving her in decision-making.

Excerpt 2: Claire, Bill, and Therapist (9 minutes into the first session)

1 C: You keep from time to time throwing out my stuff

2 B: I keep trying to clean up house, trying to maintain order of some sense

3 C: Your idea of order is different from my idea of order

4 B: Yes, I know that

5 C: Something is bothering you that's mine, there are options other than throwing it out

6 T: $\mathrm{Mm}$

7 B: Sometimes I don't ask

$8 \mathrm{~T}: \mathrm{Mm}$

9 C: No

10 B: She is my first major relationship. I've never been in a relationship before l'd met her, so I am still learning. I'm still fighting the inner uhhh inner man that thinks he

12 is still single, that I can just go ahead and

13 T: Umm that's a good way of putting it. Can I quote that? Sorry what did you, can you

14 repeat it? Inner man?

15 B: Inner man that still thinks he is single so

16 T: In terms of housework or are there other areas?

17 B: No, just doing what I want and not having to ask permission 
$18 \mathrm{~T}$ : Right right so instead of having to adapt to that whole sharing of space

19 B: Cause up until I met her l've never had to be responsible for anybody else, and it's

20 still

21 C: It's an adjustment, you are adjusting

22 B: It's an adjustment for me

23 T: So the way you put it, so you feel responsible for her?

24 B: Yes

25 T: Do you mean for cleaning up?

26 B: Not just cleaning up. I am taking into account her feelings, taking into account that

27 no, this isn't your stuff to throw or to touch to, it's hers, so it's hard

Similar to Excerpt 1, C categorizes B indirectly through describing his actions (line 1). She presents B as routinely throwing out her possessions (from time to time, he keeps...) and as someone who needs to be instructed about proper relational skills and partner conduct (there are options other than throwing it out, line 5). In response, B admits failing to ask for permission (line 7) but claims he is not to blame for it (lines 2, 10 $12,19,22)$. In excusing his actions, B appeals to his lack of skill and to his effort to become a better partner. The gender category (man) is used in conjunction with the "relational status" categorization device (single) to produce a contrast between "single men" and "partnered men." The single man "within" is who B currently is, and the partnered man is who B is striving to become. Category-bound predicates (lack, and possession, of relational skills) are evoked in B's account. The use of the single man category calls up stereotypical assumptions about single men being selfcentered and inconsiderate and a broader gender-neutral stereotype of single people being relationally unskilled and inexperienced (lines 11-12). Being inconsiderate and relationally unskilled is a state of affairs B claims he wants to change. He presents the single man in him as undesirable yet persistent. The partnered man is actively trying to defeat the residual single man (I'm still fighting the inner man that thinks he is still single). 
The construction of the self as transitioning between categories (from being single to being partnered) works to mitigate blame and frame his conduct as a temporary state rooted in his newness to coupledom. Occasional failures to take $C$ into account are seen as excusable if $B$ is actively trying to address the issue (still fighting, still learning) given that considering others' needs is new to him. He is indirectly asking people to be patient while he is learning how to be a partner. This is another example of a categorical transformation. Here, we observe $B$ constructing himself as a member of two mutually exclusive categories and in the process of transitioning between these categories, with implications for accountability.

$C$ aligns with B's construction and honors his excuse, as evident in line 21: It's an adjustment, you are adjusting. The term "adjustment" evokes common-sense knowledge that it is unreasonable to expect mastery of skills in a role without prior training or experience. This can be seen as an example of coproduction of an excuse by blamer and blamed. Overall, although the "relational orientation" is constituted as an appropriate and even desired male characteristic, it remains framed by both partners as something that is difficult for men to attain. What we can see here is a (new) sexist construction that potentially reinforces inequality in intimate relationships.

\section{Nancy and Mark}

Nancy (N) and Mark (M) sought a therapist to address "intimacy issues" attributed by $\mathrm{N}$ to M's failure to contribute more to the relationship, leaving $\mathrm{N}$ feeling overwhelmed and pressured to carry the bulk of financial and other responsibilities pursuant to $\mathrm{M}$ not working following a spinal injury. Similar to the previous excerpts, in this example we see a blame- 
account sequence, where $\mathrm{N}$ blames $\mathrm{M}$ for failing to meet his spousal

obligations and $\mathrm{M}$ excuses his actions.

Excerpt 3: Nancy, Mark, and Therapist (39 minutes into the second session)

$1 \quad \mathrm{~N}$ : But I think we decided that since he is seeing a surgeon on March 15, maybe now right now right this minute looking for a job is not good, cause we don't know what's gonna happen with that appointment. But in the meantime he does not have to sit in front of the damn TV 24/7. I am at work, how about you be the housewife, you do the dishes, you make dinner, you know like there is some cleaning that needs to be done. There is lots of stuff in the house that needs to be out of the house, go through it, get rid of it. Find things that aren't sitting in front of the TV, and so we've had a few nights where the TV's been off and we've been in peace lines omitted

M: See for years I was always been on (lists medications) and doctor always said 'you have a bad back and bla-bla-bla but we can't find where it is.' So I was disabled.

$\mathrm{T}$ : And now that's changed a little bit

M: Yeah

$\mathrm{N}$ : I think it was a mindset 'I am disabled' and he is not, cause he can go and he can change water heaters and lift water heaters, granted they are little water heaters. He's done several of them over the years, helping out at a motel, changing water heaters and stuff. He can do dry wall, he can do painting. I mean there is a lot of stuff, he's done volunteering that makes him not disabled but he's been thinking all along 'I'm so disabled, I'm so disabled'

T: $\quad$ So it's more like 'you are worth more than you give yourself credit for'

N: Yeah absolutely

T: Yeah, so 'do more'

$\mathrm{N}$ : So 'do more', yes, (laughs) 'stop sitting on your butt, do something'

$26 \mathrm{~N}$ : It's more for him. Yes it's for me, it's absolutely for me.

27 T: And for the relationship

$28 \mathrm{~N}$ : It's for the relationship. I mean he can sit on that couch and I will just bide my time 29 until the bishop (a member of the clergy that can approve divorce) says 'Okay, you 30 are done' or he can take himself off the disabled list and start thinking 'I can'

$\mathrm{N}$ and the therapist collaborate on advancing a particular conception of a socio-moral order: an intimate relationship involving two responsible adults or spouses characterized by equality and sharing of responsibilities. According to them, N's relationship with $\mathrm{M}$ departs from this standard and 
resembles one-sided caretaking. $\mathrm{N}$ and the therapist jointly attribute this violation of the norm to M's difficulty assuming and enacting responsibility. $N$ references the binary "breadwinner-housewife" (lines 4-7), proposing that it is M's turn to be the "woman" in their relationship, considering that M claims that he cannot be the "man" or family provider (the time adverb now and emphasized you implicitly present $\mathrm{N}$ as the one who has previously fulfilled this role). She lists obligations conventionally expected of members of the "housewife" category for $\mathrm{M}$ to assume. Although female and male roles and associated category-bound obligations are constituted as transferable (rather than tied to female or male bodies by nature), the heterosexual gender binary itself, or the idea that there are proper and complementary female and male roles, is left undisturbed. Though $\mathrm{N}$ is temporarily relieved of her household obligations through such role switching, if or when $\mathrm{M}$ becomes "able" to perform normative maleness, $\mathrm{N}$ is back to doing femaleness and domesticity. This might be understood as an example of sexism insofar as $\mathrm{N}$ is participating in the reproduction, rather than the dissolution, of binary gender. It is "new" in the sense that even though sharing of domestic labor is promoted, such sharing is temporary and is presumed to cease once $M$ resumes his provider duties.

M manages to mitigate blame by constructing disability as an enduring aspect of his identity (I was always; for years; lines 10-11). His self-categorization as disabled is presented not as a subjective viewpoint but as stemming from the objective, impartial, and repeatedly reasserted opinion of a medical expert (doctor always said ... so I was disabled). Inserting the category "doctor" and the doctor's direct speech (you have a bad back and bla-bla-bla but we can't find where it is) constructs his 
physical impairment as real and beyond repair. The vagueness that is deployed (bad back; bla-bla-bla) inoculates against questions about the severity and permanence of his condition, should it become specified (Potter, 1996). The construction of disability as an inherent aspect of his embodiment paints an image of $\mathrm{M}$, not as unwilling to contribute to the relationship, but as unable. Common-sense knowledge is evoked concerning differences between members of the able-bodied and disabled categories: Someone who is ill or physically impaired cannot be as productive as an able-bodied person.

N's subsequent contribution works to reallocate $M$ into the "ablebodied" category and undermine his claims of disability (lines 14-19). She develops a contrast between being disabled and thinking that one is disabled, with disability being placed in the latter domain of mind and perception. $\mathrm{N}$ claims that $\mathrm{M}$ misperceives his categorical membership and presents his assessment of his own physicality as inaccurate or contrary to evidence of his body's "actual" capacities. $\mathrm{N}$ not only directly disagrees with M's claim that he is disabled but also offers extensive evidence of his ablebodiedness. In constructing $\mathrm{M}$ as routinely performing many physically demanding jobs, $\mathrm{N}$ uses modal and iterative verbs (can do; has done; helping out), a three-part list (change water heaters, drywall, painting), and extreme case constructions (a lot of stuff, several of them). The upshot of this evidence is explicated (that makes him not disabled). $\mathrm{N}$ concludes by scripting $M$ as having held onto an erroneous and exaggerated perception of his physical inability (lines 18-19). These practices allow the reformulating of disability as a choice, rather than as a reflection of actual physicality, positioning $\mathrm{M}$ as having chosen not to contribute more as a 
spouse. $\mathrm{N}$ does not accuse $\mathrm{M}$ of malingering by pretending to be more disabled than he is; rather, she presents his claims as an honest misperception on his part.

As the next logical step following the establishment that $\mathrm{M}$ is ablebodied, $\mathrm{N}$ and the therapist propose that he increases his workload (so do more). They collectively issue a series of directives and praise to $\mathrm{M}$, instructing him to engage in work (lines 22-23). $\mathrm{N}$ affiliates both with the therapist's assessment of $\mathrm{M}$ as underestimating his capacities (yes absolutely) and the inference that a revised, corrected view of self should yield increased levels of activity. Although $M$ is clearly the target of blame, such blame is not conveyed to him directly, rather it is indirect and framed as jocular using laughter (line 23). These framings may be ways for $\mathrm{N}$ to mitigate the threats to M's person that blaming occasions (Haugh, 2013). Although the couple seem to endorse that M's conduct deviates from what is normatively expected of a spouse, they disagree about his ability to realign his conduct with this mutually endorsed morality. Whereas $\mathrm{M}$ mitigates his agency by claiming membership in the category "disabled," $\mathrm{N}$ and the therapist undermine this membership claim and challenge the notion that his conduct is excusable.

\section{Discussion}

Despite the importance of addressing contemporary sexism (Barreto \& Ellemers, 2005; Swim, Mallett, Russo-Devosa, \& Stangor, 2005), little work has been done into the ways in which subtle sexist ideas are expressed and endorsed in contemporary culture, and how people's engagement in sexism can be reduced in particular contexts. Our study indirectly helps address the perplexing question of why couples remain 
entrenched in inequality-sustaining relationships despite increasingly endorsing egalitarian norms (Gerson, 2010; Knudson-Martin \& Mahoney, 2009). It does this by providing support for the premise that inequalities persist because of partners' continued reliance on gender prejudice and stereotypes (Brandt, 2011; Glick et al., 2000; Ridgeway, 2011; Risman, 2012) and, more importantly, by showing how sexism is re-produced through everyday social interaction. While claiming to enact egalitarianism in his relationship with his wife, Jack placed limits on his ability to share domestic responsibilities by invoking incontrovertible sex differences, specifically claiming that only women can care for a newborn. Bill and Claire jointly constituted Bill as relationally unskilled and, hence, as less accountable for making unilateral decisions in their relationship. We also showed how Nancy's bid to destabilize sex differences (members of any gender category can take up provider/caretaker roles) made sexism invisible. These examples lift sexism from something enacted by men in relationships with women and present it as a set of assumptions and practices that are perpetuated by participants in interaction regardless of gender.

The study provides an alternative (discursive) conceptual and empirical foundation upon which to build research on sexism. Our focus was not on how individuals perceive others based on their group membership but on how sexism can be constituted and challenged in actual social interactions, and on how language is used flexibly and resourcefully to justify (or destabilize) gender inequalities. Discursive, contextual, and interactional analyses are especially needed in an era of shifting gender ideology, when discrete and dichotomous (either egalitarian 
or traditional) conceptions of family relations and roles will likely not suffice. Multiple, contradictory ideological forces may be at work in family and therapeutic interactions. Speakers may advance sexist claims while simultaneously drawing on egalitarian ideas (Riley, 2001; Speer \& Potter, 2000; Stokoe \& Smithson, 2001). Changing ideologies call for innovative methods of inquiry that can help examine how differential meanings of the family are constituted in specific contexts and how family members mobilize cultural knowledge (e.g., gender stereotypes or norms) in situated contexts-questions that discursive approaches are well-equipped to address. Discursive inquiry can help identify the largely taken-for-granted cultural assumptions concerning gender, caring, sharing, or domesticity that inform routine family interaction. Such underpinnings may be difficult to elicit using other methods of inquiry that presume participants' awareness of their interpretative and interactional efforts. Discursive approaches can also help compensate for the propensity within family studies to presume a uniform and static definition of the family (e.g., marital equality, sexism, roles) and shed light on how meanings are multiple, fluid, and dependent on the context.

\section{Implications for Practitioners}

Discursive studies have clear practical relevance. Increasingly, family therapists are adopting conceptions of gender inequality that treat gender as socially or discursively constructed (Dickerson, 2013; Knudson-Martin, 2015). Discursive analyses can shed light on how traditional family relations, roles, and expectations are constituted through social interaction and in specific contexts. They can highlight how conventional or stereotypical notions of gender do not merely show up as discrete and 
preformed "blocks" of meaning but are variably evoked and mobilized within families or in therapy. Specific instances of how language is used to perpetuate and challenge sexism can help therapists recognize sexist premises and dynamics of dominance in their practice and effectively challenge them.

For example, a therapist working with Jack and Emma could recognize subtle sexism in Jack's claim that as a man he is limited in his ability to provide care to a newborn. The therapist could simultaneously validate Jack's perspective and offer or invite counterarguments. A range of practices could be used to this end, including questions like these: (to Jack) Where does the idea come from that care of a newborn is limited to breastfeeding? What might be some benefits and costs for you in holding on to this idea? Looking back, if you were willing and able to become more involved as a father of your newborn daughter, what would it look like? What impact do you think your greater fatherly involvement at that time may have had on your current relationship with Emma? Some men believe that their place is at work and their female partner's place is at home. What made it possible for you to challenge this idea and become an involved father? (to Emma) What would it mean to you if Jack were to understand your experience of you being the sole caregiver of Alex after she was born? What has been the impact on you and the couple relationship of Jack increasingly becoming more involved as a father?

\section{Conclusions}

Despite endorsing egalitarian norms, some couples continue to rely on gender binaries and remain entrenched in old-fashioned patterns of gender inequality. In a postfeminist era, couples and therapists may 
presume gender equality and thus fail to recognize sexist and inequalitysustaining communications (Knudson-Martin, 2015), particularly when these claims promote egalitarian values. When gender prejudice is viewed as a matter of discourse, solutions lie not in the individual mind but in social processes that reproduce and sustain prejudice (Billig et al., 1988). Our study offers a glimpse into sexist discourse that may inspire practicing therapists and researchers to contribute to the body of knowledge accessible through discursive inquiry within family studies and family therapy. Discursive analyses can help identify and resist taken-for-granted binary and stereotypical notions of gender, and be used to assist couples in developing mutually supportive relationships and gender flexibility (Gerson, 2010). These studies support the consideration of new ways of thinking about the complexities of the family and gender relations, and the roles each of us play in engendering stasis or evolution.

\section{Acknowledgements}

The authors would like to thank clients and therapists, and other individuals who helped develop the archive of therapy sessions mobilized in this article. This work was supported by funding from the Canada Foundation for Innovation and the Social Sciences and Humanities Research Council of Canada. Special thanks to Clare MacMartin, Eleftheria Tseliou, Christopher Quinn-Nilas, Kevin VanDerZwet Stafford, William Cooke, Lorna Martin, and journal reviewers for their helpful comments.

\section{References}

Augoustinos, M. (2016). Re-theorizing prejudice in social psychology: From cognition to discourse. In C. Tileagă \& E. Stokoe (Eds.), Discursive 
psychology: Classic and contemporary issues (pp. 243-256). New York: Routledge.

Augoustinos, M., \& Every, D. (2010). Accusations and denials of racism: Managing moral accountability in public discourse. Discourse \& Society, 21, 251-256.

Barreto, M., \& Ellemers, N. (2005). The burden of Benevolent Sexism: How it contributes to the maintenance of gender inequalities. European Journal of Social Psychology, 35, 633-642.

Barreto, M., Ellemers, N., Piebinga, L., \& Moya, M. (2010). How nice of us and how dumb of me: The effect of exposure to benevolent sexism on women's task and relational self-descriptions. Sex Roles, 62(7-8), 532-544.

Bates, L. (2016). Everyday sexism. New York: Thomas Dunne Books.

Becker, J. C., \& Swim, J. K. (2012). Reducing endorsement of benevolent and modern sexist beliefs: Differential effects of addressing harm versus pervasiveness of benevolent sexism. Social Psychology, 43, 127-137.

Billig, M., Condor, S., Edwards, D., Gane, M. J., Middleton, D., \& Radley, A. (1988). Ideological dilemmas: A social psychology of everyday thinking. London, UK: Sage.

Blodorn, A., O'Brian, L. T., \& Kordys, J. (2012). Responding to sex-based discrimination: Gender differences in perceived discrimination and implications for legal decision making. Group Processes \& Intergroup Relations, 15(3), 409-424. 
Boeri, T., Del Boca, D., \& Pissarides, C. (Eds.) (2005). Women at work. An economic perspective. Oxford, UK: Oxford University Press.

Brandt, M. J. (2011). Sexism and gender inequality across 57 societies. Psychological Science, 22, 1413-1418.

Brinkman, B. G., \& Rickard, K. M. (2009). College students' descriptions of everyday gender prejudice. Sex Roles, 61(7-8), 461-475.

Butler, J. (2004). Undoing gender. New York: Routledge.

Buttny, R. (1990). Blame-account sequences in therapy: The negotiation of relational meanings. Semiotica, 78(3-4), 219-247.

Cole, E. R. (2009). Intersectionality and research in psychology. American Psychologist, 64, 170-180.

Condor, S., Figgou, L., Abell, J., Gibson, S., \& Stevenson, C. (2006).

"They're not racist": Prejudice, denial mitigation and suppression in dialogue. British Journal of Social Psychology, 45, 441-462.

Crenshaw, K. (1991). Mapping the margins: Intersectionality, identity politics, and violence against women of color. Stanford Law Review, 43(6), 1241-1299.

Davis, S. N., \& Greenstein, T. N. (2009). Gender ideology: Components, predictors, and consequences. Annual Review of Sociology, 35, 87105.

Dickerson, V. C. (2013). Patriarchy, power, and privilege: A narrative poststructural view of work with couples. Family Process, 52, 102 114. 
Deutsch, F. M. (2007). Undoing gender. Gender and Society, 21(1), 106127.

Edwards, D. (1998). The relevant thing about her: Social identity categories in use. In C. Antaki \& S. Widdicombe (Eds.), Identities in talk (pp. 15-33). London, UK: Sage.

Edwards, D., \& Potter, J. (1992). Discursive psychology. London, UK:

Sage.

Edwards, D., \& Stokoe, E. H. (2004). Discursive psychology, focus group interviews and participants' categories. The British Journal of Developmental Psychology, 22, 499-507.

Gerson, K. (2010). The unfinished revolution: How a new generation is reshaping family, work, and gender in America. New York: Oxford University Press.

Gill, R. (2011). Sexism reloaded, or, it's time to get angry again!. Feminist Media Studies, 11(1), 61-71.

Glick, P., \& Fiske, S. T. (2011). Ambivalent sexism revisited. Psychology of Women Quarterly, 35(3), 530-535.

Glick, P., Fiske, S. T., Mladinic, A., Saiz, J. L., Abrams, D., Masser, B. et al. (2000). Beyond prejudice as simple antipathy: Hostile and benevolent sexism across cultures. Journal of Personality and Social Psychology, 79, 763-775.

Haugh, M. (2013). Im/politeness, social practice and the participation order. Journal of Pragmatics, 58, 52-72. 
Hester, S., \& Eglin, P. (1997). Membership categorization analysis:

Introduction. In S. Hester \& P. Eglin (Eds.), Culture in action: Studies in membership categorization analysis (pp. 1-24). Boston, MA: University Press of America.

Hester, S., \& Hester, S. (2012). Categorical occasionality and transformation: Analyzing culture in action. Human Studies, 35, 563581.

Housley, W., \& Fitzgerald, R. (2015). Introduction to membership categorization analysis. In R. Fitzgerald \& W. Housley (Eds.), Advances in membership categorization analysis (pp. 1-22). London, UK: Sage.

Ingraham, C. (2006). Thinking straight, acting bent: Heteronormativity and homosexuality. In K. Davis, M. Evans, \& J. Lorber (Eds.), Handbook of gender and women's studies (pp. 307-321). London, UK: Sage.

Jayyusi, L. (1984). Categorization and the moral order. London, UK: Routledge.

Jefferson, G. (1991). List construction as a task and resource. In G. Psathas (Ed.), Interactional competence (pp. 63-92). New York: Irvington.

Kan, M. Y., \& Gershuny, J. (2010). Gender segregation and bargaining in domestic labour: Evidence from longitudinal time-use data. In L. Scott, R. Crompton, \& C. Lyonette (Eds.), Gender inequalities in the 21st century: New barriers and continuing constraints (pp. 153-173). Cheltenham, UK: Edward Elgar. 
Knudson-Martin, C. (2015). When therapy challenges patriarchy: Undoing gendered power in heterosexual couple relationships. In C. KnudsonMartin, M. A. Wells, \& S. K. Samman (Eds.), Socio-emotional relationship therapy (pp. 15-26). New York: American Family Therapy Academy.

Knudson-Martin, C., \& Mahoney, A. R. (2009). Couples, gender, and power: Creating change in intimate relationships. New York: Springer.

Lorber, J. (Ed.) (2012). Gender inequality: Feminist theories and politics (5th ed.). New York: Oxford University Press.

Mannino, C. A., \& Deutsch, F. M. (2007). Changing the division of household labor: A negotiated process between partners. Sex Roles, 56(5-6), 309-324.

McCall, L. (2005). The complexity of intersectionality. Signs: Journal of Women in Culture and Society, 30(3), 1771-1800.

McPhillips, R., \& Speer, S. A. (2015). Sexist discourse. In K. Tracy (Ed.), International encyclopedia of language and social interaction (pp. 1349-1354). Oxford, UK: Wiley-Blackwell.

Monahan Lang, M., \& Risman, B. (2006). Blending into equality: Family diversity and gender convergence. In K. Davis, M. Evans, \& J. Lorber (Eds.), Handbook of gender and women's studies (pp. 287-304). London, UK: Sage.

Morse, J. M. (2008). 'What's your favorite color?' Reporting irrelevant demographics in qualitative research. Qualitative Health Research, 18(3), 299-300. 
O'Neill, K., \& LeCouteur, A. (2014). Naming the problem: A membership categorization analysis study of family therapy. Journal of Family Therapy, 36(3), 268-286.

O'Reilly, M. (2014). Blame and accountability in family therapy: Making sense of therapeutic spaces discursively. Qualitative Psychology, 1(2), 163-177.

Overall, N. C., Sibley, C. G., \& Tan, R. (2011). The costs and benefits of sexism: Resistance to influence during relationship conflict. Journal of Personality and Social Psychology, 101(2), 271-290.

Potter, J. (1996). Representing reality. London, UK: Sage.

Ridgeway, C. L. (2011). Framed by gender: How gender inequality persists in the modern world. New York: Oxford University Press.

Riley, S. C. (2001). Maintaining power: Male constructions of 'feminists' and 'feminist values'. Feminism \& Psychology, 11(1), 55-78.

Risman, B. J. (2012). Gender as a social structure. In J. Lorber (Ed.), Gender inequality: Feminist theories and politics (5th ed., pp. 220230). New York: Oxford University Press.

Robles, S. J. (2015). Extreme case (re)formulation as a practice for making hearably racist talk repairable. Journal of Language and Social Psychology, 34, 390-409.

Rudman, L. A., \& Heppen, J. B. (2003). Implicit romantic fantasies and women's interest in personal power: A glass slipper effect? Personality and Social Psychology Bulletin, 29(11), 1357-1370. 
Sacks, H. (1974). On the analyzability of stories by children. In R. Turner (Ed.), Ethnomethodology: Selected readings (pp. 216-232). Harmondsworth, UK: Penguin Books.

Sacks, H. (1992). Lectures on conversation (Vols. 1 and 2). Oxford, UK: Blackwell.

Schmitt, M. T., Branscombe, N. R., Postmes, T., \& Garcia, A. (2014). The consequences of perceived discrimination for psychological wellbeing: A meta-analytic review. Psychological Bulletin, 140(4), 921948.

Sharp, E. A., \& Keyton, K. (2016). Caught in a bad romance? The negative effect of normative dating and marital ideologies on women's bodies. Sex Roles, 1-13.

Sidnell, J., \& Stivers, T. (2013). The handbook of conversation analysis. Oxford, UK: Wiley-Blackwell.

Speer, S., \& Potter, J. (2000). The management of heterosexist talk: Conversational resources and prejudiced claims. Discourse \& Society, 11, 543-572.

Speer, S. A. (2002). Sexist talk: Gender categories, participants" orientations and irony. The Journal of Sociolinguistics, 6, 347-377.

Speer, S. A. (2015). Responding to -isms. Journal of Language and Social Psychology, 34, 464-470.

Stapleton, K. (2015). Accountable preferences? Discourse, identity, and the anti-prejudice norm. Journal of Language and Social Psychology, 35(5), 491-514. 
Stokoe, E. (2012). Moving forward with membership categorization analysis: Methods for systematic analysis. Discourse Studies, 14(3), 277-303.

Stokoe, E. (2015). Identifying and responding to possible -isms in institutional encounters: Alignment, impartiality, and the implications for communication training. Journal of Language and Social Psychology, 34, 427-445.

Stokoe, E., \& Attenborough, F. (2015). Prospective and retrospective categorization: Category proffers and inferences in social interaction and rolling news media. In R. Fitzgerald \& W. Housley (Eds.), Advances in membership categorization analysis (pp. 51-70). London, UK: Sage.

Stokoe, E., \& Smithson, J. (2001). Making gender relevant: Conversation analysis and gender categories in interaction. Discourse \& Society, 12(2), 217-244.

Swim, J. K., Aikin, K. J., Hall, W. S., \& Hunter, B. A. (1995). Sexism and racism: Old-fashioned and modern prejudice. Journal of Personality and Social Psychology, 68(2), 199-214.

Swim, J. K., Mallett, R., Russo-Devosa, Y., \& Stangor, C. (2005). Judgments of sexism. A comparison of the subtlety of sexism measures and sources of variability in judgments of sexism. Psychology of Women Quarterly, 29, 406-411.

Tileagă, C., \& Stokoe, E. (Eds.) (2016). Discursive psychology: Classic and contemporary issues. New York: Routledge. 
Tougas, F., Brown, R., Beaton, A. M., \& Joly, S. (1995). Neosexism: Plus Fa change, plus c'est pareil. Personality and Social Psychology Bulletin, 21, 103-118.

Watson, R. (2015). De-reifying categories. In R. Fitzgerald \& W. Housley (Eds.), Advances in membership categorization analysis (pp. 23-50). London, UK: Sage.

Whitehead, K. A. (2015). Everyday antiracism in action: Preference organization in responses to racism. Journal of Language and Social Psychology, 34, 374-389.

Whitehead, K. A., \& Stokoe, E. (2015). Producing and responding to -isms in interaction. Journal of Language and Social Psychology, 34, 368373. 